\title{
Digilogue Zone: Indigenous and Contemporary Media and Technology in Higher Music Education in Kenya
}

\author{
Emily Achieng' Akuno \\ Technical University of Kenya
}

Kenya's children experience two forms of technology and media as they access and interact with information: the indigenous technology and media that are derived from their cultural surrounding and modern electronic technology and media that are readily available thanks to social platforms and media of mass communication. The term "digilogue" describes this merger of modern electronic media and technology with indigenous, community-based resources and technology. Nowhere is this mix of indigenous and modern technology more evident than in music practice. Diverse music genres integrate elements of indigenous music practices with modern resources and processes. This merger of technologies is also evident in music teaching and learning practices. This article examines the presence and types of technology, its use in music practice, and its application for music teaching and learning. It calls for the integration of relevant, accessible and creativity-enhancing technology in teaching and learning so that music education can lead to the intellectual development of learners.

Keywords: indigenous media, resources, modern technology, music, music education.

I

use the term digilogue to capture the environment that merges modern electronic media and technology with indigenous, community-based resources and technology. In terms of the digital/analogue dichotomy, the overall technoscape in Kenya is one characterised by extremes. On one end, there are parts of the country that are far from any internet network coverage and where even the widely used mobile telephone technology is not efficient. In these areas, one has to look for a spot where the network is strong, locally referred to as phone booth. ${ }^{1} \mathrm{On}$ the other extreme, there are areas fitted with very strong internet access, with wireless connectivity in coffee houses and restaurants, learning institutions, offices and a large number of cyber cafés within easy reach of anyone needing to go online. At

(C) Emily Achieng' Akuno 2018. The content of this article is the sole responsibility of the author. The ACT Journal and the Mayday Group are not liable for any legal actions that may arise involving the article's content, including, but not limited to, copyright infringement. 
first glance, the use of electronic media and access to information and communication technology appears widespread, but closer examination shows more use among youth, most of whom are engaged in learning programmes.

Recently, the Kenyan government has aimed at opening up access to information by facilitating knowledge acquisition and exchange through technology and media. One example of this has been through school-wide tablet initiatives, where learners in the first year of primary school (1st grade) are each supplied with a tablet to ensure better computer literacy. Though Information and Communication Technology (ICT) and computer-based equipment are readily a part of Kenyan youth experience, they are not the only forms of technology available to them. Every community has its own indigenous knowledge base, and the technology that facilitates the acquisition and application of this knowledge. There are resources and tools that serve needs within communities, appearing with varied levels of concentration in different parts of the country. This difference is not only on account of distance from urban hubs, but also the level of interaction with modern communication and lifestyle. The indigenous and modern resources often serve side-byside in the performance of tasks of daily living. A basic example is the presence of a food blender and a $\mathrm{mbuzi}^{2}$ in the same kitchen.

Nowhere is this mix of indigenous and modern technology more evident than in music practice. There is a strong component of indigenous music practices evident in contemporary music making, including indigenous music material, idioms, and music-based pieces that call for the use of resources familiar to the communities from which the music comes. An example of this is T. K. Njoora's Songs from Kenya for piano and orchestra (premiered in Nairobi, Kenya at the Nairobi Orchestra's Easter Concert 1994) that uses Kenyan lullabies as the thematic material. There is a practice of combining these resources, especially music instruments, with modern (electronic) band equipment in the performance of popular music. Recordings will sometimes feature such a melange of instruments and material, such as evident in Auma by Kayamba Africa (http://redmp3.su/). This piece features the orutu (Luo fiddle) and ohangla (set of drums), and electric guitars as the backdrop to harmonised male voices singing in call-and-response structure.

The practice of merging technologies is not confined to the industry alone. It is entrenched in the teaching and learning of music in schools, with the secondary school curriculum in Kenya asking for specific content from Kenyan traditions as

Akuno, Emily Achieng'. 2018. Digilogue zone: Indigenous and contemporary media and technology in higher music education in Kenya. Action, Criticism, and Theory for Music Education 17 (1): 8196. doi:10.22176/act17.1.81 
well as other sources (KIE 2012, 55-81). The same is replicated in the public universities that offer music courses, including the Technical University of Kenya and Kenyatta University.

\section{Music Technology and its Access}

From the radio and gramophone records that were produced in Kenya shortly after World War II (Ondieki 2010), Kenya's airwaves are now filled with sounds generated and enhanced by electronic means. The instruments of music that are widely used also have capacities that enlarge musical possibilities in terms of pitch and timbre. These provide a rich environment for teaching and learning, while conversely challenging the cultural content of music produced locally through expansion of pitch and timbral capacities.

In both rural and urban communities, learners' interaction with technological devices range from complex to simple. The use ranges from that of generating to storing or recording sound material. The types of resources put in use range from those that are within the user's immediate environment, i.e., what is accessible to specialized resources that are used by a more elite clientele.

Since World War II, there has been a mushrooming of recording studios in the urban centres of Kenya. River Road in Nairobi harbours a large number of building spaces where the various activities of music production happen, from recording to mastering, duplication, and printing. The new music that makes it onto the radio and television stations, which normally is but a fraction of the total generated, points to a very large quantity of created material. These studios, in both commercial areas and private homes, are equipped with machines that range from very complex recording, editing, and mixing units, such as found at Kete Bul studios at the GoDown Arts Centre in Nairobi, to more modest equipment or the bare minimum which, instead of using live band instruments, would be facilitated by an electronic keyboard with in-built accompaniment and a laptop with editing software. Access to FM stations and YouTube provides avenues for dissemination of generated material while providing access to other sound sources and applications that can be used to enhance an individual's music making project. Michele Bisonga, for example, a university music student, is one of the many who has a YouTube channel and are fully engaged with the music industry through the use of this type of technology. in higher music education in Kenya. Action, Criticism, and Theory for Music Education 17 (1): 8196. doi:10.22176/act17.1.81 
This abundance of and ease of access to technological devices for music making-though facilitating the production of large quantities of music material-calls to question issues of creativity and meaning that are traditionally associated with the generation and display of music material. ${ }^{3}$ It may further throw into disarray the whole vision and mission of music education, where it appears that one need not spend time in music classes if they can grasp a few techniques for dealing with mechanised or electronic equipment to come up with fast selling music products. The youth successfully replicate any type of music style accessed through these abundant computer-based resources, and the same make it easy to edit and produce recordings.

Modern technology might be seen to put at risk creativity and collective efforts in music making and learning that characterise musicianship in much of Kenya's indigenous practice. The accessible sound tracks reduce the stress of learning new music, making this almost effortless, and thus compromising music literacy development. In trying to replicate the sounds heard in recordings used as learning aids, learners develop habits (unintentionally) that affect technique, such as those observed in my voice classes where students try to emulate certain vocal qualities but end up with questionable tones that demonstrate strain on and misuse of vocal apparatus. This is likely to affect all music performance activities in which students resort to IT-based teaching aids without prior technical instruction.

This not only impacts on performance, but also on music creation. Where composition is conceived of as the art of selecting, organising and arranging sounds, it may need theoretical grounding that the technological-composer may not have acquired. Similarly, with YouTube at one's fingertips, there is ready access to music for study. In analysis, for example, one does not have to turn the analysis class into a performing class for students to access the music under study. It can quickly be downloaded from YouTube. This, paradoxically, compromises the total experience of music in class. Learning may be very passive, despite the better access to sound resources, which should advantage today's students who constantly wear earphones.

One of my cherished reasons for teaching music is teaching for independent inquiry. This is satisfied through the teaching of music reading towards performance and perception. The internet serves this through online music libraries and stores for ease of access to scores, some that can be bought instantly as PDF documents. The paradox is that there are often recordings that learners can access, and in higher music education in Kenya. Action, Criticism, and Theory for Music Education 17 (1): 8196. doi:10.22176/act17.1.81 
so they can learn the music by rote and be dependent on another's rendition and interpretation. The learner's development and style are both compromised in a case such as this. (I have been advised by a student that $\mathrm{s} /$ he played a piece a certain way because that's the way a particular musician played it on YouTube.)

The modern media and technology therefore, in my experience, pose a challenge to the implementation of teaching and learning in schools and colleges, demanding that a fair balance be achieved between their use and their non-use in learning situations. I find it prudent to consider one's philosophy for teaching and learning music as the guide to mediation that will let the technology be a tool that enhances performance-of both teaching towards efficacy and learning towards meaningful utilisation of resources. The widespread use and remarkable capabilities of technology and media devices affect learners' perception of music making. It therefore impacts learners' expectation of how music instruction should be conceptualised, defined, and delivered. All of these affect what happens in the classroom, and whether or not there will be a music classroom. They hence have a bearing on what goes down in terms of planning for music learning. The universities are an important point of departure for this discourse. In Kenya, since the universities prepare teachers for all levels of learning, and practitioners for the industry, they have a big impact on how things function in society.

\section{Conceptual Matters}

Music

In Kenyan settings, music finds a place in all significant events, including political rallies, football matches, weddings, and funerals. This leads to and is supported by the participatory (Oehrle 1993) nature of music making, a phenomenon that ensures broad contribution to the form and content of music by the audience. In this participatory mode, the context of music performance determines its content, because it is generated for a particular function. Music as a phenomenon is therefore presented in formats that vary from situation to situation, noting that Kenya is not a culturally homogenous geographic space.

With 42 linguistic communities in Kenya, the activities that result in the action and object referred to as music vary. There is an abundance of song material, and the local dialects' word for 'music' often translates back into the English word song (Akuno 1997). Song and singing therefore characterise the basic activity that one in higher music education in Kenya. Action, Criticism, and Theory for Music Education 17 (1): 8196. doi:10.22176/act17.1.81 
can call music. In different areas, there is equipment that is played in the process of singing, either as accompaniment or as co-contributors to the music phenomenon. These instruments of music have different geographic distribution in the country, dictated by the vegetation of the region and the economic activities of the people who live there, the latter also affected by the climatic conditions. There are percussion instruments, with drums of all sizes and shapes and other shaken and struck objects of music making. The drums are played in sets with a few or many other percussion instruments, notably jingles, bells, wooden blocks, and metal rings. In regions such as the coastal strip and the western lake region of Kenya, such ensembles include wind and string instruments as well. However, one prevailing instrument is the human voice, for much of the music is sung.

The performance of music includes body movement. When dancing, some of the décor and costume contribute to the music as they jingle or rub against each other and cause friction, thereby producing rhythmic accompaniment. Dancing, as a rhythmic activity, contributes to the definition of the rhythm of the music. Music is therefore a composite activity where song, instrument, dance, and costume converge in an artistic cultural expression.

\section{Music Education}

This participatory nature of music has implications for the teaching and learning process. When planned with the learning context in mind, it ought to apply a participatory approach, where learners input into the activities that result in concept acquisition and skill development. Since the context of music making defines the content of what is called music, it informs the selection of the materials of music. Music's inherent qualities reflect the circumstances that give it birth. These qualities are indicative of its value, because they reflect and portray its functional role. The role is aligned to the place of the performance of the music (context and value), and leads to an understanding of its definitive elements explained as idioms, structure and resources, including who performs the music. These characterise the practice of music and provide resources for its teaching and learning.

This article conceptualises music education as the act and process of facilitating the growth of an individual for meaningful participation in musical, musicbased, or music-driven activities, as a member of a social group that finds meaning in that (music) activity. With music making being context-driven (above), gaining

Akuno, Emily Achieng'. 2018. Digilogue zone: Indigenous and contemporary media and technology in higher music education in Kenya. Action, Criticism, and Theory for Music Education 17 (1): 8196. doi:10.22176/act17.1.81 
of meaning in music making is also context-based. An individual is enabled to fully participate in social events by being able to carry out relevant music-based tasks that are appropriate to him/her. In order to do this, the individual acquires relevant skills, notably perceptual skills for discrimination of sounds through listening in order to identify their part and fulfil their role in the participatory activity. The individual also develops manipulative skills useful for the playing of instruments. Besides the development of skills, learning involves the building of a repertoire of music literature to cater for various music making contexts. This is made possible by sound knowledge of the cultural context of music making, information about the people, their activities, relationships, mores, norms, history, and world view.

\section{Technology in Music Practice}

Technology is presently touching all aspects of life (Koç 2005). In education, it allows us to accommodate students' learning needs, because it can be manipulated to create a quasi-flexible learning environment and programmes. Technology has been viewed as a comprehensive concept, covering both the artefacts and application of knowledge, hence both material and skills of an operation (Herbst and Tracey 2003). It is often applied in contexts where objects enhance people's capabilities, so that one is able to perform certain tasks that would not otherwise be possible (Herbst and Tracey 2003, 279). This positions technology as a tool and means to higher achievement, greater efficiency and better production. The type of technology at hand reflects the comparative socio-economic status of the users.

The practice of music includes the application of technology that is deemed relevant for the activity. When a new device is introduced, there is great impact on the practice of music, because musicians have to negotiate its usage and manipulation. Such a move has a ripple effect, impacting on not only music performance, but also composition because music creators have to work with its capacities in mind. And so, "technological change, once implemented, is capable of exercising complex influence" (Herbst and Tracey 2003, 280). Since the practice of music influences the way it is taught, introduction of (new) music technology affects not just the way music is taught, but also what constitutes music teaching and learning.

The changes mentioned above have been observed in the use of electronic keyboard instruments in Kenyan church music. There have arisen distinct music styles that are associated with different denominations, on account of music style and 
instrumentation (for example, see Catholic choral music and a Seventh-Day Adventist group). Being a common and widely accepted instrument by churches, the electronic keyboard (popularly called keys) enjoys a popularity that provides prime ground for the investigation of what might constitute music education. How do the players of these instruments acquire pertinent skills for their activities, for example, and what is their knowledge of the concepts behind the actions they perform?

Suffice to say that indigenous music practice has had technology that is indigenous to its makers. This indigenous technology includes that of constructing and maintaining instruments of music (Herbst and Tracey 2003, 280). This is a process that requires technological skills and practical knowledge of the mechanism of the instrument, to determine what material is acoustically suited for its various parts from what may be available in the locality. Instruments are made by individuals, often the players. Music education would ideally include, over and above the art of handling the instruments, the teaching of music instrumental technology. The specialised knowledge involved in this process has to do with perception and discernment regarding material for construction, based on the understanding of the function of each part of the instrument and the desired sound qualities. Further, there is an intimate connection to the instrument that is associated with this personal construction. It is not only the construction technique that matters, but a human element exists that is tied to first-hand knowledge of the musical culture that gives birth to the instrument and within which it will function. These are significant skills and knowledge that are yet to be fully explored in higher music education in Kenya. The strides so far made by both Kenyatta University and the Technical University of Kenya, though commendable, need enhancing through a stronger presence of this content in the syllabus.

The indigenous tools for the construction of these instruments are now complemented by objects made from different materials. This technological advancement contributes to ease of construction and maintenance of instruments through more efficient tools. The way it is applied in Kenya ensures that it does not distance the human and the instrument because it does not remove the human contact with the instrument in the course of the instrument's development and creation. At Kenyatta University, for example, music students use equipment at the Department of Physics workshop to make indigenous music instruments, a process that ensures merger of traditional resources with modern tools. 
A drastic application of technology occurs when materials for the construction of instruments have to change. Zake (1986) reports that instead of wooden resonators, metal basins have been used, and that the strings for lyres and harps are now often made from nylon. Original materials are responsible for the idiomatic, cultural timbre that is specific to a music instrument, which is also responsible for its cultural role, especially those of a ritual nature. The sound quality of, for example the Kilumi drums of the Akamba people of Kenya, is essential to their therapeutic role of evoking spirit possession for the purposes of healing. The introduction of new materials results in new sounds that alter the sonic atmosphere created by the music. These may result in an alienation of the music from its authentic cultural role, robbing it of its intended meaning and value.

The replacement of authentic, natural material with synthetic or technologically fabricated ones is an example of foreign elements creeping into cultural practices, because the process of making the instruments must also change to accommodate the new materials. It also denies learners the experience of indigenous technologies. The use of a metal basin as resonator means that the whole process of walking to the forest, identifying a large enough tree, felling it, chopping a sizeable portion from the trunk, curing it, scooping off the pith to create the basin is now not applicable. That is a technical practice that, without its context of practice, becomes obsolete.

Oral cultures rely on repetition to relay music material. This provides scope for review of the music content, thereby ensuring relevance to the occasion for which it is performed. Technology has made it possible to reproduce sounds mechanically, thereby introducing an element of alienation into music making (Herbst and Tracey 2003, 282-3). This is magnified today by the expanded scope and reach of recording technology, where one keyboard and electronic gadgets replace the band in sound generation. In performance, many singing groups sing to/alongside a full recording of their music, apart from the use of back up tracks. In this instance, the performer is denied both a full ensemble experience and the opportunity to fully engage with the work of art. Performance, referred to by Andang'o (2009) as recreation, is scope for expression and re-production of music. Reproduction of this nature needs a flexible environment to realise, which the straight jacket of prerecorded backup may not offer. Creativity is developed and enhanced through music performance that is receptive and sensitive to the context of its performance. Just like water taking the colour of the container which holds it, so does music take in higher music education in Kenya. Action, Criticism, and Theory for Music Education 17 (1): 8196. doi:10.22176/act17.1.81 
the shape and atmosphere of the event of its occurrence. A big question is how to mitigate this in the face of growing global cultural exchange and assimilation.

A graver concern is the adverse effect of technology through the 'lifeless' music processes and products that are consequences of devices of mass production and popular culture. This has resulted in the transformation of what is essentially an expression of life from a representation of reality to a commodity. Since technology is procedures and tools for enhancing experiences, an informed selection and utilisation of materials and procedures should enable the music classroom to prepare learners for efficiency in their engagement with music materials and participation in music activities. In selecting types of technology, the aim is to further the reach and impact of what is available to learners and practitioners, thereby expanding their cultural experience. Technology can make the music classroom a fertile cultural space and not a barren enclosure devoid of the multiple modes of cultural experience that music is. If technology is to build cultural experience, it should facilitate participatory music making and learning.

\section{Technology in the Higher Music Education Classroom}

Among other activities that inform human development, education entails skills development and concept assimilation. The latter demands the employment of culturally relevant or adaptable technological tools and technical skills in the creation, practice, and teaching of music. Achola and Akuno $(2013,31)$ list technology employed in schools as: computer, electronic keyboard and others, such as recorders. These are primarily used in composition, teaching piano performance skills, downloading resource material for the history classes, playback for the teaching of aural skills, demonstrating scales, etc. In terms of prevalence, Achola and Akuno (2013, 31) report the recorder and electronic keyboard as most common instruments/technology in school. They recognise that some parts of the curriculum re-

quire diverse teaching facilities to supplement the traditional approach to music instruction, calling for proper resourcing for success in teaching and learning.

Achola's (2016) ongoing research focuses on technology in higher music education. Three short years after the publication above, the technoscape has changed, influenced heavily by what learners carry to class and the readily accessible innovative practices elsewhere on the globe. Software for sound generation is accessed by students on their smartphones and tablets, into which they also download music in higher music education in Kenya. Action, Criticism, and Theory for Music Education 17 (1): 8196. doi:10.22176/act17.1.81 
tracks for personal consumption. These, for learning purposes, even make the electronic keyboard redundant, because a chord progression, for example, can be programmed into the software and repeated several times.

The learners' music reference material is from far and wide, thanks to YouTube. The classroom soundscape is diverse. In my analysis class, for example, students easily log onto websites for resources. They also readily access Windows Media Player where they store any ripped music for further reference. My attempts to dictate excerpts for them to transcribe as visual stimulus for analysis appear rather archaic, especially for music whose score they can access and which may not be in my library.

A synthesis of indigenous and modern technology in the music classroom has proved possible, and is effective when matters of relevance are considered in the selection of materials for teaching. At both Kenyatta University and the Technical University of Kenya, this ensures that the learning experiences benefit from resources and procedures in the cultural and modern world, because of using materials and techniques from both worlds. The relevance refers to matching resources with the content under study. To achieve this, a bi-musical conceptualisation of music learning has been applied. This leads to a practice that recognises the inherent technologies in each type of music studied and an endeavour to utilise the same for skills development.

The curriculum in both universities calls for learners' exposure to the concepts and processes of music of African and Western cultures. With this background of bi-musicality as a component of music scholarship, educators will ensure that learners are exposed to indigenous resources. While exposing learners from an early age to digital technology as has started through the tablet programme, educators will deliberately give learners access to the technology that is embedded in the indigenous music knowledge. Music and other scholars are concerned about the erosion of African culture. Exposing learners to indigenous resources should provide knowledge and opportunity for the assimilation of elements of their cultural heritage, and hopefully contribute to the shaping of their identity. Identity goes beyond self-perception because it contributes to how one perceives phenomena in their environment. Early learning provides the framework for negotiating later experiences. An education that validates certain experiences allows a learner to value them. When indigenous music and its resources form part of an individin higher music education in Kenya. Action, Criticism, and Theory for Music Education 17 (1): 8196. doi:10.22176/act17.1.81 
ual's early music education, the individual's 'culture' is defined by that music's context as well as any other that they encounter in life. Sacred music, for example, formed part of my childhood, and has remained a definitive element in my choice of the music activities in which I participate. This explains in part how identity is crucial for musical development.

At the two universities, the practice of taking theoretical and practical tuition in African and Western music ensures that learners are familiar with the resources that facilitate engagement with these two. In mixing indigenous and modern technology, higher music education creates a rich music learning experience, where the local provides grounding for the learners in their cultural practices, thereby providing the vocabulary with which to negotiate the external knowledge and technology. Glocal becomes a relevant term for the cultural experience in the music classroom.

In learning, technology has been found to provide a context for working with multiple senses. It is known to provide a context for 'improving the working memory, self-regulation and cognitive flexibility' (Portowitz, Peppler, and Downton 2014, 242). As useful learning support, the use of different types of technology provides tools for enhancing assimilation as well as opportunity and success in self-driven work. It also facilitates the creation and maintenance of a broad knowledge base. This 'cognitive flexibility' is crucial in the modern world where the industry demands adaptation to circumstances needing application of skills in diverse contexts. An ability to grasp the technologies that facilitate working with indigenous music makes it possible for the graduate of our music education programme to function in and make meaningful contribution to the local music scene. The rate at which knowledge (read technology) increases is worth noting. Kenyan higher music education is therefore striving to 'respond to the changing demands of twenty-first century learners' (Portowitz et al. 2014, 243). The learners are exposed to new technologies that change the learning and teaching environment. One could believe the possibility of teacherless learning due to the abundance of self-teaching software in the market. The software enhances music production with, for example, ready-made pre-structured harmonic patterns, phrases, and accompaniment patterns that cut out the strain of contriving one's own ideas for composition or the production of a song. The higher music education classroom in Kenya will do well to incorporate the equivalent technology for the Kenyan music content (as they do with music from other regions), and to ensure in higher music education in Kenya. Action, Criticism, and Theory for Music Education 17 (1): 8196. doi:10.22176/act17.1.81 
that learners are still able to make music as opposed to 'accessing' already made music.

\section{Conclusion-the Digilogue Zone}

Feuerstein and Klein's mediated learning (Portowitz et al. 2014, 245) is a concept that promotes active interaction between the teacher and the learner. Such an atmosphere encourages learners to use what is learnt in new situations. This approach is valuable for a learning environment that merges indigenous and modern technology, such as happens in Kenya. The (knowledgeable) teacher ensures an integration of the two types of media in learning. The interface between indigenous and digital technology, the digilogue zone provides a rich learning environment where the cultural context of the music whose content is the focus of study, is explored through appropriate tools. In keeping a firm hold on the indigenous media, one of Kenya's aims of education is met, that of propagating culture. By lavishly applying modern technology, learning becomes relevant in today's socio-cultural space. Moreover, it mediates entry into the professional practice by exposing learners to modern tools of the trade.

There are music programmes at the Technical University of Kenya where the curriculum contains concepts and skills that ensure learners' development through exposure to both indigenous and modern (digital) technology. In the first year, each semester has a course unit on computer technology, starting with the general basics of computers, introducing the hardware and literacy and progressing to application of computer software in the music context. The computer skills provide opportunity for familiarisation with the equipment of information and communication technology. In subsequent semesters of the music programmes, learners are introduced to music writing software, followed by the use of music-based technology. Bucci et al. (2003) report a similar procedure at Ohio State University at Mansfield, where there is a deliberate move to integrate technology in learning. Running concurrently with this and students' own digital technology is the more traditional field of Kenyan (and African) music. Indigenous technology is encountered in course units that expose learners to the different music practices and the technology that facilitates them. This ensures a cultural grounding, upon which experimentation and exploration with digital media can occur. With the institution's technical orientation, the focus on practical application of knowledge with 
relevant technological devices and technical skills provides the context for the digital-indigenous technology mix.

A noted advantage of this mix of modern (digital) and indigenous technology is the widened scope for exploration seen as a thrill with trying new sound combinations, either in solo or ensemble fora. It is recognised that technology abides where there is need for it. The introduction of technology along with the knowledge and skills to use the technology is a valuable engagement. Noting that digital technology is the way of this world, the objectives of (higher) music education need to be articulated in ways that will ensure adequate knowledge and skills development. The tooling of the individual to function effectively in a music environment in 21st century Kenya requires exposure to both indigenous and modern technology if music education is to serve the purpose of propagating culture while enabling the learner to operate in the contemporary economy. It is in getting grounded in our culture that we, as Kenyans, can sustain our unique identity while contributing our rich heritage to the wider world of music scholarship and practice. The challenge for education planners is the provision of resources and modalities that will sustain a bi-musical learning system, where technology in all its hues thrives, learners appreciate both indigenous and modern, each is accorded its rightful place with an identified role, and none is deemed inferior.

This calls for the integration of relevant, accessible and creativity-enhancing technology in teaching and learning, so that music education leads to 'a wider range of intelligence' (Koç 2005, 1). The fields of music have many such technologies, both modern and indigenous, digital and analogue, which support the holistic experience of music. They are essential for the teaching and learning of music.

\section{About the Author}

Emily Achieng' Akuno is Professor of Music at the Technical University of Kenya, and Deputy Vice-Chancellor of the Co-operative University of Kenya, both in Nairobi. Her teaching and research lean towards cultural relevance in music teaching, and the application of music for the development of literacy in children. 


\section{References}

Achola, Malachi Apudo. 2016. Pedagogic framework to transform students' learning by using digital technologies to support the development of higher education (HE) music programmes. Ongoing Doctoral Research. University of Cambridge, UK.

Achola, Malachi Apudo and Akuno, Emily Achieng'. 2013. The role of technology in music education in Kenya. Kenya Journal of Musical Arts 1: 24-37.

Akuno, Emily Acheing'. 2005. Issues in music education in Kenya. Nairobi: Emak Music Services.

Akuno, Emily Acheing'. 1997. The use of indigenous Kenyan children's songs for the development of a curriculum and pedagogy for music in the primary school. Kingston-Upon-Thames: Kingston University.

Andang'o, Elizabeth Achieng'. 2009. Music in early childhood education: Development of a multi-cultural music education programme. Unpublished $\mathrm{PhD}$ Thesis. Nairobi: Kenyatta University.

Bucci, Terri Teal, Jean Copenhaver, Lynn Johnson, Barbara Lehman, and Thomas O'Brien. 2003. Technology integration: Connections to educational theories. Contemporary Issues in Technology and Teacher Education 3 (1): 26-42.

Herbst, Theo, and Andrew Tracey. 2003. Technology and African music studies. In Musical Arts in Africa, edited by Anri Herbst, Meki Nzewi, and Kofi Agawu, 279-92. Pretoria: University of South Africa.

Kenya Institute of Education. 2012. Secondary syllabus volume IV. Republic of Kenya Ministry of Education

Koç, Mustafa. 2005. Implications of learning theories for effective technology integration and pre-service teacher training: A critical literature review. Journal of Turkish Science Education 2 (1): 2-18.

Oehrle, Elezabeth. 1993. Education through music: Towards a South African approach. International Journal of Music Education 10 (3): 255-61.

Ondieki, Donald Otoyo. 2010. An analysis of Kenyan popular music 1945-1975 for the development of instruction materials for music education. Unpublished PhD Thesis. Nairobi: Kenyatta University.

Portowitz, Adena, Kylie Peppler, and Mike Downton. 2014. In Harmony: A technology-based music education model to enhance musical understanding and general learning skills. International Journal of Music Education 32 (2): 24260 .

Zake, George Senoga. 1986. Folk music of Kenya. Nairobi: Uzima Press.

Akuno, Emily Achieng'. 2018. Digilogue zone: Indigenous and contemporary media and technology in higher music education in Kenya. Action, Criticism, and Theory for Music Education 17 (1): 8196. doi:10.22176/act17.1.81 


\section{Notes}

${ }^{1}$ reminiscent of the old public telephone booths that would be placed strategically at shopping areas and bus stops for public access.

${ }^{2}$ Mbuzi is a gadget for extracting the flesh from the coconut shell used by women at the coastal strip of Kenya.

3 see Akuno 1997 and 2005 on music's significance being tied to its socio-cultural function, and the content being determined by the context

Akuno, Emily Achieng'. 2018. Digilogue zone: Indigenous and contemporary media and technology in higher music education in Kenya. Action, Criticism, and Theory for Music Education 17 (1): 8196. doi:10.22176/act17.1.81 